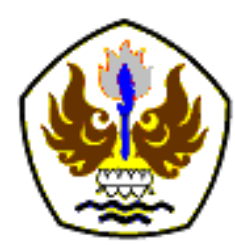

INFOMATEK

Volume 18 Nomor 2 Desember 2016

\title{
KARAKTERISASI MATERIAL BUCKET TEETH PADA EXCAVATOR UNTUK PENINGKATAN KUALITAS DAN PEMBUATAN
}

\author{
Bukti Tarigan ${ }^{*}$ \\ Program Studi Teknik Mesin \\ Fakultas Teknik - Universitas Pasundan
}

\begin{abstract}
Abstrak: Bucket teeth adalah komponen attachment yang sering digunakan pada heavy equipment salah satunya yaitu bucket wheel excavator, yang fungsinya untuk material handling. Prinsip kerja bucket wheel excavator adalah continuous excavators, namun dalam pengoperasinnya bucket teeth sering terjadi kendala yang dapat mengganggu proses produksi. Salah satu kendala yang sering terjadi adalah keausan pada bucket teeth. Bucket teeth harus mempunyai ketangguhan dan kekuatan bahan yang tinggi, sehingga dapat mempengaruhi life time dari komponen tersebut dan mengurangi down time. Dalam penelitian ini akan dibahas mengenai karakterisasi material bucket teeth pada BWE (Bucket wheel excavator) dengan menggunakan metoda pengamatan metalografi, pengujian komposisi kimia, dan pengujian kekerasan yang berguna untuk mengetahui harga kekerasan pada bucket teeth dengan, demikian dapat memberi informasi kepada industri lokal dan perusahaan yang menggunakan bucket teeth mengenai spesifikasi material yang cocok untuk pembuatan bucket teeth. Adapun hasil pengujian metalografi, analisa komposisi kimia bucket teeth adalah termasuk material baja paduan sedang yang mengandung silicon, mangan dan krom yang mempunyai sifat tangguh, tahan korosi dan tahan aus. Diliahat dari struktur mikro dan kekerasan mempunayai struktur martensit temper dan harga kekerasanya rata-rata 468 BHN. Dengan adanya porositas dan permukaan specimen yang kasar dapat diperkirakan bahwa proses pembuatan bucket teeth menggunakan proses pengecoran (casting), dan diikuti dengan pengerasan (hardening) dan temper.
\end{abstract}

Kata kunci: Bucket teeth, Excavator

\section{PENDAHULUAN}

\subsection{Bucket Wheel Excavator[1]}

Bucket wheel excavator (BWE) adalah alat berat yang digunakan di tambang terbuka. BWE paling efektif digunakan di tanah lembek yang tidak banyak mengandung batuan keras. Komponen utama BWE adalah roda berputar besar yang dipasang pada sebuah lengan raksasa. Ujung roda ini kemudian dipasangi

*) bukti.tarigan@yahoo.com semacam ember besi (bucket) dengan gigigigi logam dipinggiran bucket yang digunakan untuk menggali tanah.

Bucket ini terus berputar seiring putaran roda (wheel) yang kemudian dirancang untuk menumpahkan muatannya pada sabuk berjalan (belt conveyor) yang terdapat di badan BWE. BWE disebut juga sebagai continuous excavators karena dapat menggali secara menerus tanpa terputus. Bucket yang 
terus berputar akan memberikan tingkat penggalian maksimal plus tidak diperlukannya lagi alat angkut tambahan, sebab mineral yang digali langsung diangkut oleh belt conveyor.

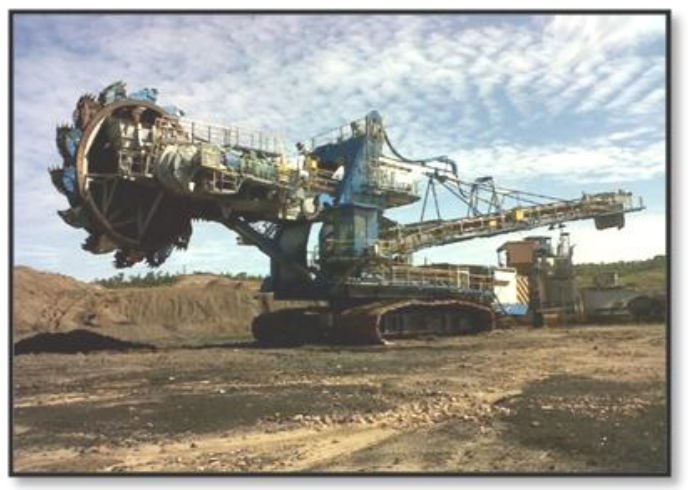

Gambar 1

Bucket Wheel Excavator

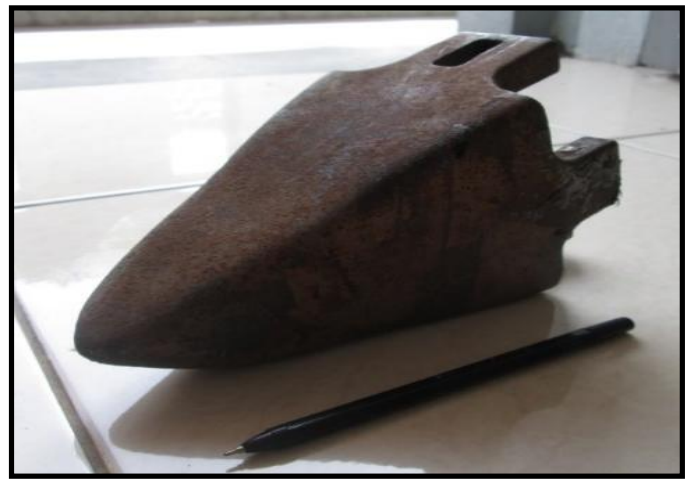

Gambar 2

Bucket Teeth BWE

Ini jelas sangat menguntungkan karena akan memberikan tingkat produksi yang tinggi dan penghematan biaya pembelian alat tambahan. Kelemahan BWE terutama disebabkan oleh harga alat yang sangat tinggi serta karakteristik BWE yang hanya cocok digunakan di tanah yang relatif lunak.

\subsection{Faktor-faktor yang mempengaruhi produksi $B W E[2]$}

Dalam melakukan kegiatan penggalian, banyak hal yang mempengaruhi pencapaian produksi, diantaranya:

1. Faktor alat, adapun faktor-faktor yang mempengaruhi penggalian atau kapasitas penggalian BWE adalah:

a. Karakteristik bahan dan bucket

b. Kecepatan Penggalian

c. Desain kapasitas bucket dan jumlah bucket

d. Jumlah dan bentuk gigi bucket

2. Faktor alam

a. Kekerasan Material

Kekerasan material mempengaruhi produksi karena kemampuan BWE (bcm/menit) merupakan fungsi dari angka pengisisan bucket. Semakin tinggi angka pengisian bucket, maka semakin besar produksi yang dicapai. BWE hanya dapat melakukan penggalian secara efisien jika material yang digali memiliki kekerasan dibawah $5000 \mathrm{kpa}$.

\subsection{Baja}

Baja adalah paduan besi dengan karbon dimana kadar karbonnya maksimum $2 \%$. Unsur paduan lain yang biasa ditambahkan selain karbon adalah mangan (manganese), 
krom (chromium), vanadium, dan tungsten. Dengan memvariasikan kandungan karbon dan unsur paduan lainnya, berbagai jenis kualitas baja bisa didapatkan. Penambahan kandungan karbon pada baja dapat meningkatkan kekerasan (hardness) dan kekuatan tariknya (tensile strength), namun di sisi lain membuatnya menjadi getas (brittle) serta menurunkan keuletannya (ductility).

\subsubsection{Klasifikasi Baja Carbon (carbon steel)[3]}

Baja Karbon merupakan baja dengan paduan utamanya adalah karbon. Baja ini diklasifikasikan berdasarkan jumlah karbonnya yaitu:

A. Baja karbon rendah (low carbon steel) Baja ini memiliki kandungan karbon kurang dari $0,25 \%$ C. Sifatnya mudah ditempa, mudah dimesin (machining) dan dilas. Baja karbon rendah memiliki keuletan dan ketangguhan yang baik tetapi kekerasan dan keausannya rendah. Baja karbon rendah biasa digunakan untuk komponen bodi mobil, struktur bangunan, jembatan dan lain-lain.

\section{B. Baja karbon sedang (medium carbon steel)}

Baja ini memiliki kekuatan yang lebih tinggi dari pada baja karbon rendah. Sifatnya sulit untuk dibengkokkan, dilas, dipotong. Baja karbon sedang mengandung kadar karbon
0,25\%C-0,5\%C. Penggunaan dengan kandungan $0,30 \%-0,40 \%$ C digunakan pada connecting rods, crank pins, and axles, kandungan $0,40 \%-0,50 \%$ C digunakan untuk car axles, crankshafts, rails, boilers, auger bits, and screwdrivers.

\section{Baja karbon tinggi (high carbon steel)}

Baja karbon tinggi adalah baja yang mengandung kadar karbon 0,5\%C-1,7\%C. Memiliki sifat tahan panas yang tinggi, kekerasan tinggi, namun keuletannya rendah. Baja karbon tinggi mempunyai kekuatan tarik yang tinggi dan banyak digunakan untuk material tools. Berdasarkan jumlah karbon yang terkandung didalam baja maka baja karbon ini banyak digunakan dalam pembuatan pegas dan alat-alat perkakas.

\subsubsection{Baja Paduan (Alloy steel)}

Tujuan dilakukan penambahan unsur yaitu:

- Untuk menaikkan sifat mekanik baja (kekerasan, keliatan, kekuatan tarik dan sebagainya)

- Untuk menaikkan sifat mekanik pada temperatur rendah

- Untuk meningkatkan daya tahan terhadap reaksi kimia (oksidasi dan reduksi)

- Untuk membuat sifat-sifat spesial

Baja paduan yang diklasifikasikan menurut kadar karbonnya dibagi menjadi: 
- Low alloy steel, jika elemen paduannya $\leq$ $2,5 \%$

- Medium alloy steel, jika elemen paduannya $2,5-10 \%$

- High alloy steel, jika elemen paduannya > $10 \%$

Baja paduan juga dibagi menjadi dua golongan yaitu baja campuran khusus (special alloy steel) \& highspeed steel. Semua unsur paduan yang ditambahkan dapat mempengaruhi sifat-sifat setiap jenis baja, sebagai contoh dapat meningkatkan ketahanan korosi, ketahanan aus, dsb.

\subsubsection{Diagram Fasa Besi Karbon (Fe-C)[4]}

Fasa didefinisikan sebagai bagian dari bahan yang memiliki struktur atau komposisi tersendiri. Diagram fasa $\mathrm{Fe}-\mathrm{C}$ atau biasa disebut diagram kesetimbangan besi karbon merupakan diagram yang menjadi parameter untuk mengetahui segala jenis fasa yang terjadi di dalam baja dengan segala perlakuannya. Diagram fasa berfungsi untuk memprediksi fasa-fasa yang terbentuk pada berbagai kondisi temperatur seiring dengan pertambahan kadar karbon. Pada diagram fasa seperti terlihat pada gambar 3 , muncul larutan padat $(\delta, \alpha, \gamma)$ atau disebut besi delta $(\delta)$, austenite $(\gamma)$, dan ferrite $(\alpha)$.

Ferrite mempunyai struktur kristal BCC (Body Centered Cubic) dan austenite mempunyai struktur kristal FCC (Face Centered Cubic) sedangkan besi delta mempunyai struktur kristal BCC pada suhu tinggi.

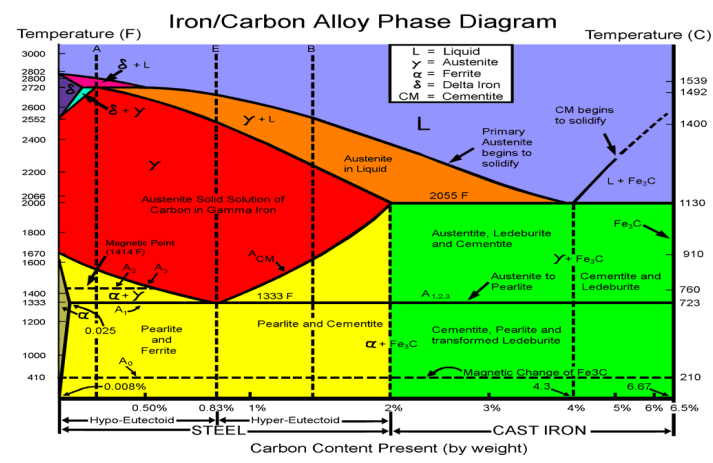

Gambar 3

Diagram fasa besi karbon (Fe-C) [5]

Ada beberapa hal yang harus diperhatikan di dalam diagram fasa $\mathrm{Fe} 3 \mathrm{C}$ yaitu perubahan fasa ferrite atau besi alpha, austenite atau besi gama, cementite atau karbida besi, perlite, dan martensite.

1. Ferrite atau besi alpha ( $\alpha)$

Ferrite merupakan modifikasi struktur besi murni pada suhu ruang, dimana ferrite menjadi lunak dan ulet karena ferrite memiliki struktur BCC (Body Centered Cubic), maka ruang antar atom-atomnya adalah kecil dan padat.

\section{Austenite atau besi gama $(\mathrm{Y})$}

Austenite merupakan modifikasi struktur besi murni dengan struktur FCC (face centered Cubic) yang memiliki jarak atom lebih besar dibandingkan ferrite meskipun demikian, rongga-rongga pada struktur FCC hampir tidak dapat menampung atom karbon dan penyisipan atom karbon akan mengakibatkan 
tegangan dalam struktur sehingga tidak semua rongga dapat terisi, dengan kata lain daya larutnya menjadi terbatas.

\section{Karbida dan cementite}

Karbida besi adalah paduan besi karbon, dimana pada kondisi ini karbon melebihi batas larutan sehingga membentuk fasa kedua atau karbida besi yang memiliki komposisi Fe3C. Karbida pada pearlite akan meningkatkan kekerasan baja. Sifat dasar cimentite adalah sangat keras.

\section{Pearlite}

Pearlite merupakan campuran antara ferrite dengan karbida (cementite). Laju pendinginan yang lambat dapat menghasilkan pearlite kasar dengan sifat dan ketangguhan yang rendah. Sedangkan bila laju pendinginan agak cepat dapat menghasilkan pearlite halus yang bersifat keras dan tangguh. Pearlite memiliki bentuk seperti pelat-pelat yang disusun bergantian antara cementite dan ferrite. Pada baja hypoeutektoid, struktur mikro terdiri dari daerah-daerah pearlite yang dikelilingi oleh ferrite.

\section{Martensite}

Martensite adalah suatu fasa yang terjadi karena pendinginan yang sangat cepat dan terjadi pada suhu dibawah eutektoid tetapi masih diatas suhu ruang karena struktur austenite FCC tidak stabil sehingga akan berubah menjadi struktur BCT (Body Centered Tetragonal) secara serentak. Pada reaksi ini tidak terjadi difusi tetapi pergeseran. Martensite terbentuk karena trasformasi tanpa difusi sehingga atom-atom karbon seluruhnya terperangkap dalam larutan super jenuh. Keadaan ini menimbulkan distorsi pada struktur kristal martesitedan membentuk BCT. Maka martensite akan menjadi kuat dan keras tetapi sifat getas dan rapuh menjadi tinggi. Kekerasan yang meningkat ini sangat penting karena dapat menciptakan baja yang keras, tahan gesekan dan deformasi. Pada suhu dibawah suhu eutektoid dalam waktu yang cukup lama, larutan karbon yang lewat jenuh ini terus berubah menjadi bentuk ferrite dan karbida yang lebih stabil. Proses ini dikenal dengan nama tempering.

$M$ (martensit) $\alpha+$ karbida $\rightarrow$ (martensit temper)

Mikrostruktur ( $\alpha+$ karbida) yang terjadi tidak berbentuk lamel seperti perlit. Martensit temper ini lebih tangguh sehingga banyak digunakan.

\subsection{Perlakuan Panas (Heat Treatment)}

Heat Treatment (perlakuan panas) adalah salah satu proses untuk mengubah struktur logam dengan jalan memanaskan specimen pada elektrik terance (tungku) pada temperature rekristalisasi selama periode waktu tertentu kemudian didinginkan pada media pendingin seperti udara, air, air garam, 
oli dan solar yang masing-masing mempunyai kerapatan pendinginan yang berbeda-beda. Faktor yang mempengaruhi dalam proses heat treatment adalah laju pemanasan (rate of heating), waktu pemanasan (holding time), dan media pendingin.

\section{METODOLOGI}

\subsection{Diagram Alir Pengujian}

Dalam pengerjaan penelitian ini dilakukan beberapa tahap pengerjaan, seperti terlihat pada Gambar 4.

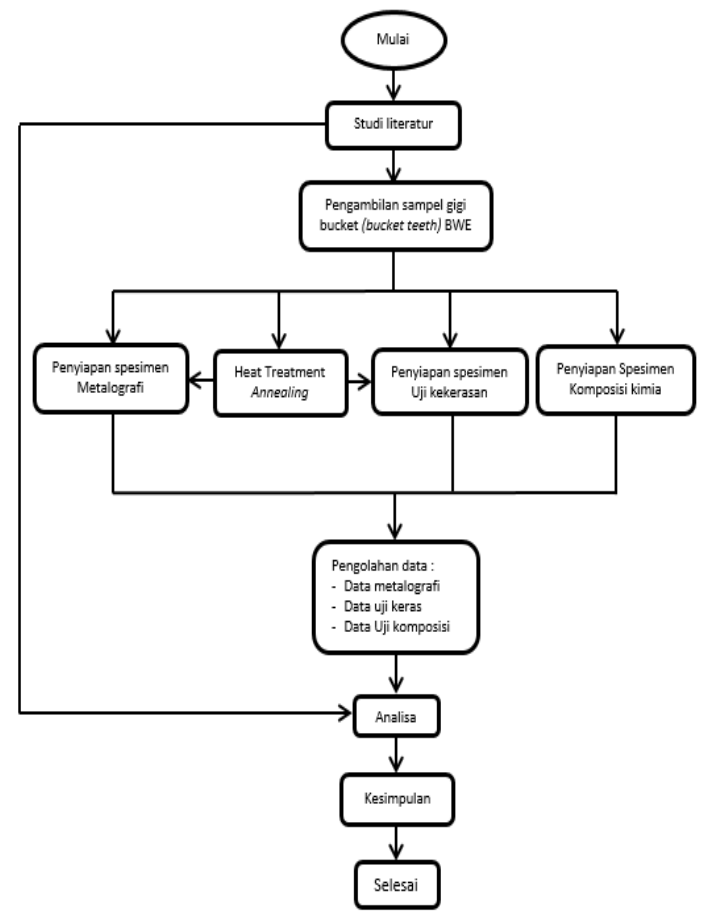

Gambar 4

Diagram alir pengujian

\subsection{Metalografi}

Pengambilan sample menggunakan mesin potong (cutting wheel) dengan menjaga temperature pemotongan tetap dingin dan deformasi pemotongan sangat kecil untuk tidak mempengaruhi struktur dan sifat aslinya.

Pengamatan metalografi dilakukan untuk pengamatan mako dan mikro menggunakan mikroskop optik kemudian dilakukan pemotretan, yang bertujuan untuk mengetahui jenis material, fasa-fasa yang terkandung, dan memperkirakan proses produksi yang dilakukan dan juga untuk pengukuran ketebalan lapisan. Pemeriksaan metalografi bertujuan untuk mengetahui struktur mikro dan fasa-fasa yang terkandung dalam material, dengan urutan sbb:

1. Pemotongan

2. Pembingkaian (mounting)

3. Penggerindaan(Grinding)

4. Pemolesan (Polishing)

5. Pengetsaan (Etching), Nital

6. Pengamatandanpemotretanstruktur mikro dan Makro

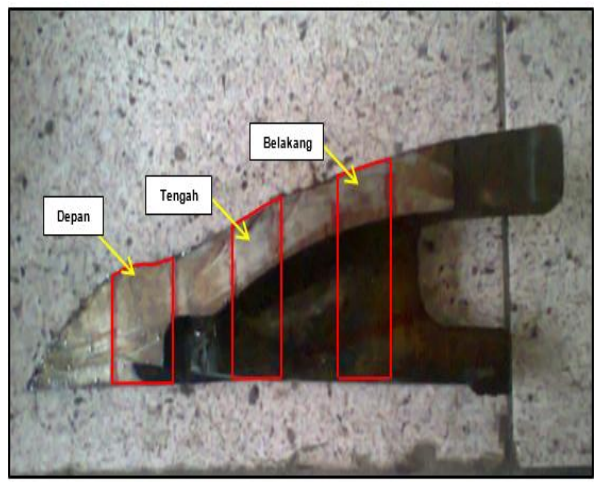

Gambar 5

Posisi pengambilan sampel 


\subsection{Pengujian Kekerasan}

Pengujian kekerasan bertujuan untuk mengetahui tingkat kekerasan pada suatu material. Setelah diperkirakan bahwa proses pembuatan bucket teeth BWE dilakukan dengan proses cor dan tidak ada pengerasan, selanjutnya dipilih cara untuk uji keras yaitu dengan cara Brinell. Uji keras Brinell cocok untuk produk cor karena produk cor mempunyai struktur atau bentuk butir yang besar dan produk cor mempunyai porositas, untuk menjangkau bentuk butir yang besar dan adanya porositas maka digunakan uji keras Brinell yang mempunyai penampang indentor yang besar.

Spesimen yang digunakan untuk uji keras ini adalah kondisi as it is dan annealing arah pemotongan transversal dari bucket teeth. Indentor yang digunakan adalah bola baja berukuran $10 \mathrm{~mm}$ dengan beban uji $3000 \mathrm{kgf}$.

\subsection{Proses Perlakuan Panas (Heat} Treatment)

Pada penelitian ini dilakukan haet treatment salah satunya yaitu anneling yang bertujuan untuk menganalisa struktur material dengan metode kuantitatif sehingga dapat membandingkan kadar karbon hasil uji komposisi material dengan metode kuantitatif adapun langkah-langkah pengerjaan proses anneling adalah sebagai berikut :

1. Pemotongan spesimen.
2. Sebelum spesimen dimasukkan kedalam tungku, dilakukan proses preheating agar tidak terjadi distorsi dan shock treatment. Panaskan tungku sampai temperatur $700^{\circ} \mathrm{C}$, kemudian masukkan spesimen ke dalam tungku sampai temperatur $900^{\circ} \mathrm{C}$ dengan holding time \pm 30 menit.

3. Setelah itu matikan tungku dan dinginkan spesimen di dalam tungku sampai mencapai suhu kamar.

4. Keluarkan spesimen dan lakukan pengujian selanjutnya.

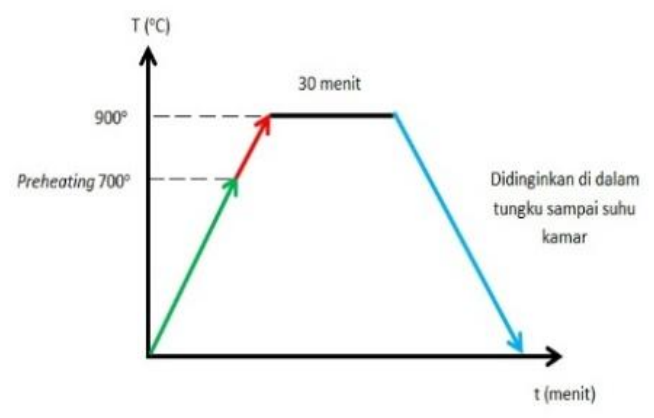

Gambar 6

Diagram proses perlakuan panas (annealing).

\subsection{Pengujian Komposisi Kimia}

Untuk mengetahui unsur-unsur yang terkandung pada bucket teeth maka dilakukan uji komposisi kimia dengan metoda optical emission spectrometer menggunakan pengeksitasi berupa loncatan bunga api (spark). Untuk uji komposisi spesimen yang digunakan adalah bagian-bagian dari bucket teeth yang tidak dijadikan spesimen uji metalografi dan uji keras. 
Spesimen untuk uji komposisi ini harus lebih besar persyaratan minimun adalah $18 \mathrm{~mm} x$ $18 \mathrm{~mm}$. Hal ini dilakukan karena probe mesin uji komposisi berdiameter $18 \mathrm{~mm}$. Spesimen harus dapat menutupi seluruh permukaan probe. Selanjutnya spesimen permukaannya diratakan menggunakan ampelas.

\section{HASIL DAN PEMBAHASAN}

\subsection{Data Analisa struktur makro}

Pengambilan sample dilakukan pada bucket teeth BWE dengan posisi seperti pada Gambar 7, dan pengamatan makro dilakukan pada bagian tertentu saja dengan menggunakat larutan etsa $\mathrm{HCL} 10 \mathrm{ml}, \mathrm{HNO}_{3}$ $5 \mathrm{ml}, \mathrm{H}_{2} \mathrm{O} 5 \mathrm{ml}$. Diambil tiga titik pengujian yaitu bagian depan specimen arah pengamatan transversal dan bagian belakang specimen arah pengamatan transversal.

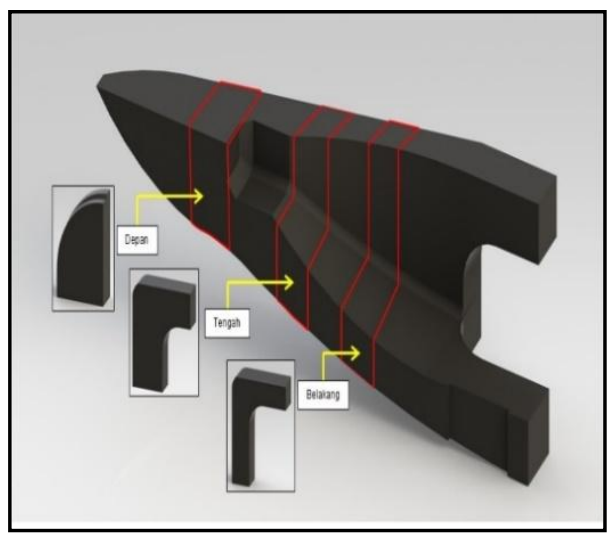

Gambar 7

Posisi pengambilan sampel arah transversal.
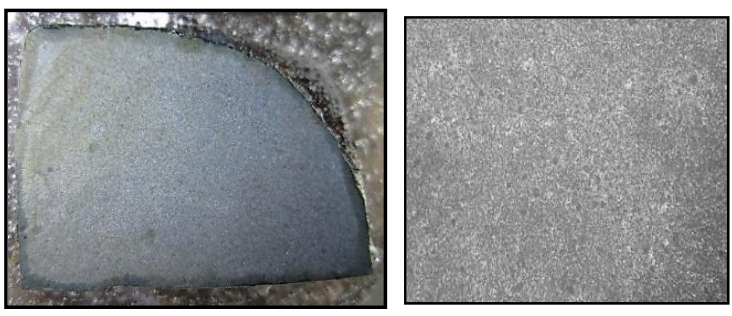

Gambar 8

Struktur makro bucket teeth BWE bagian depan, terlihat butir yang menyebar.
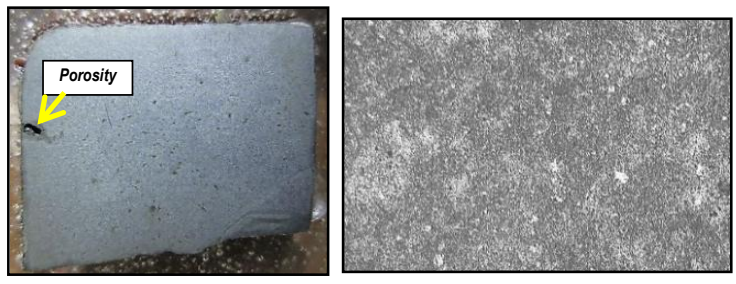

Gambar 9

Struktur makro bucket teeth BWE bagian tengah,terlihat butir yang menyebar dan porosity
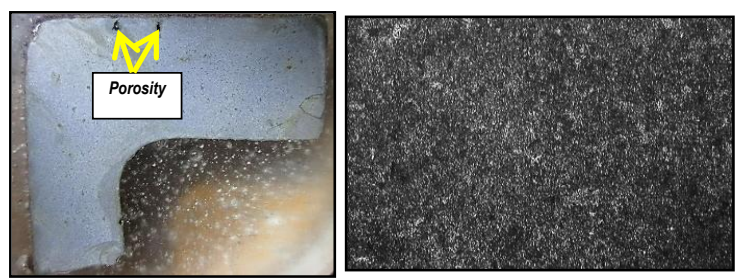

Gambar 10

Struktur makro bucket teeth BWE bagian belakang,terlihat butir yang menyebar dan porosity.

\subsection{Data dan Analisa struktur mikro}

Untuk pengujian metalografi mikro pada bucket teeth BWE (Bucket Wheel Excavator) digunakan spesimen potongan kondisi as it is dibagian depan, tengah, belakang dan kondisi annealing posisi pemotongan transversal. 


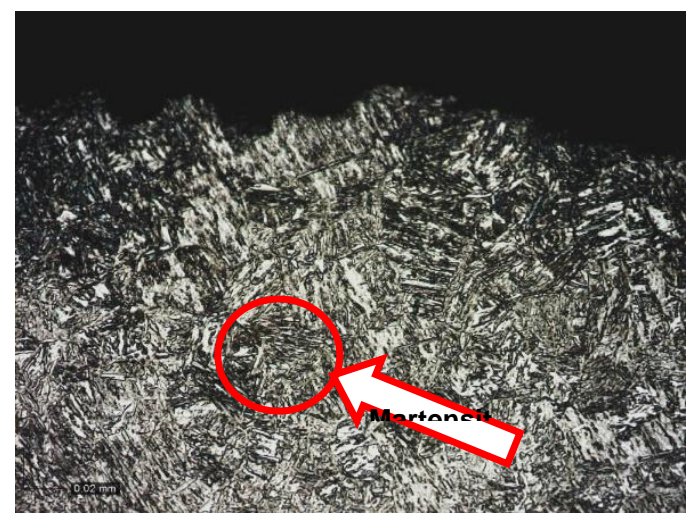

Gambar 11

Struktur mikro bucket teeth bagian depan posisi sisi,terlihat fasa martensit temper + ferrit, (600x)

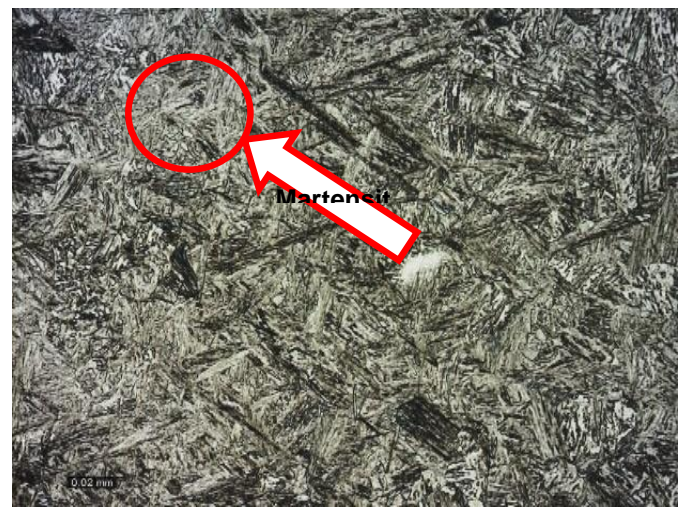

Gambar 12

Struktur mikro bucket teeth bagian depan posisi tengah,terlihat fasa martensit temper + ferrit, $(600 x)$

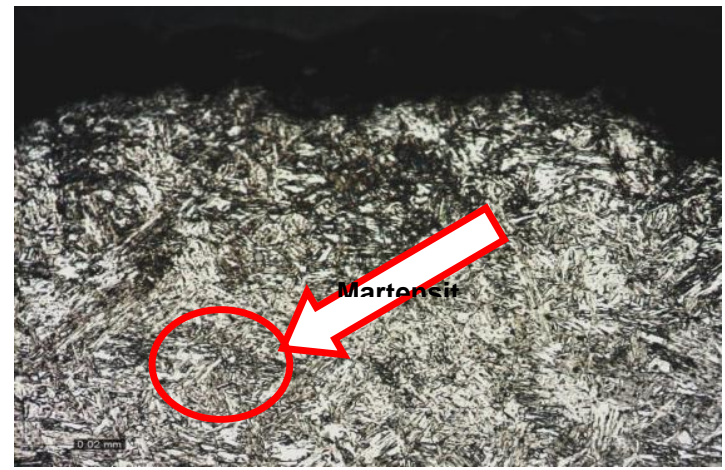

Gambar13

Struktur mikro bucket teeth bagian tengah posisi sisi,terlihat fasa martensit temper + ferrit, (600x).

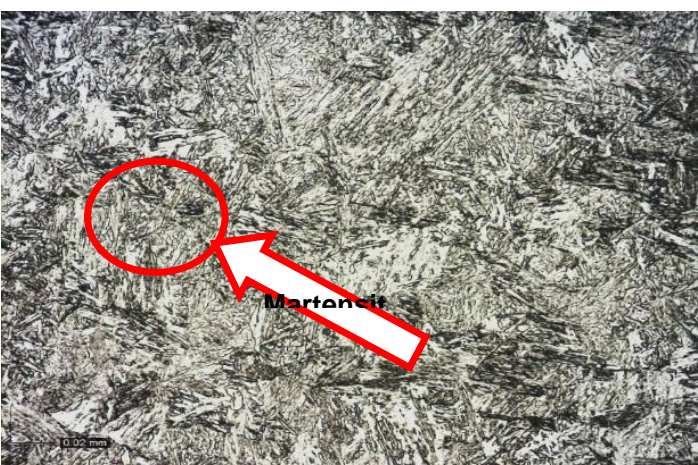

Gambar 14

Struktur mikro bucket teeth bagian tengah posisi tengah, terlihat fasa martensit temper + ferrit, (600x).

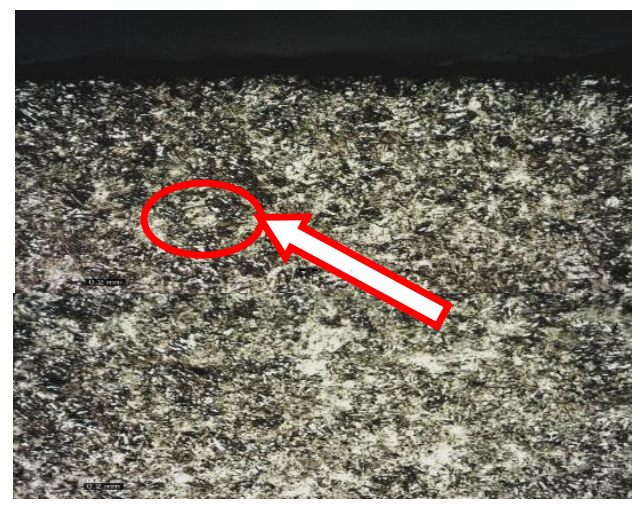

Gambar 15

Struktur mikro bucket teeth bagian belakang,terlihat fasa martensit temper + ferrit, $(75 x)$

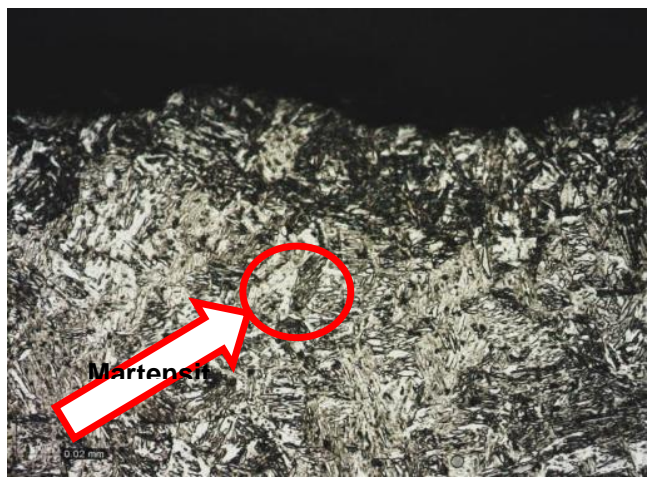

Gambar 16

Struktur mikro bucket teeth bagian belakang posisi sisi,terlihat fasa martensit temper + ferrit, (600x). 


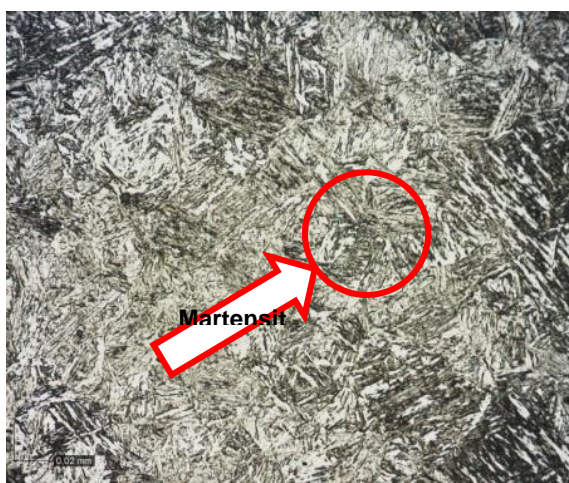

Gambar 17

Struktur mikro bucket teeth bagian belakang posisi tengah,terlihat fasa martensit temper + ferrit,(600x).

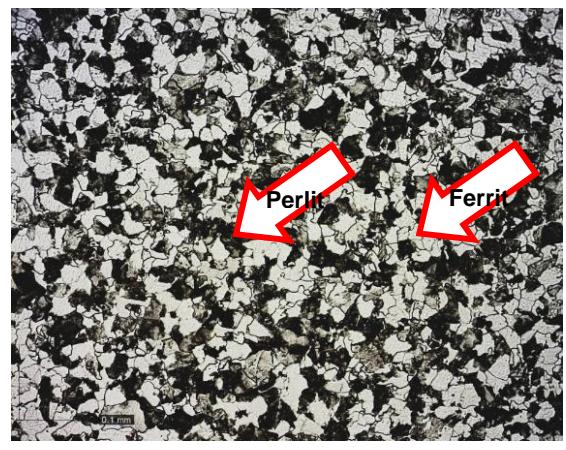

Gambar 18

Struktur mikro kondisi annealing, terlihat fasa ferrit (putih) + perlit (hitam)

\subsection{Prediksi Kadar Karbon Pada Bucket}

\section{Teeth}

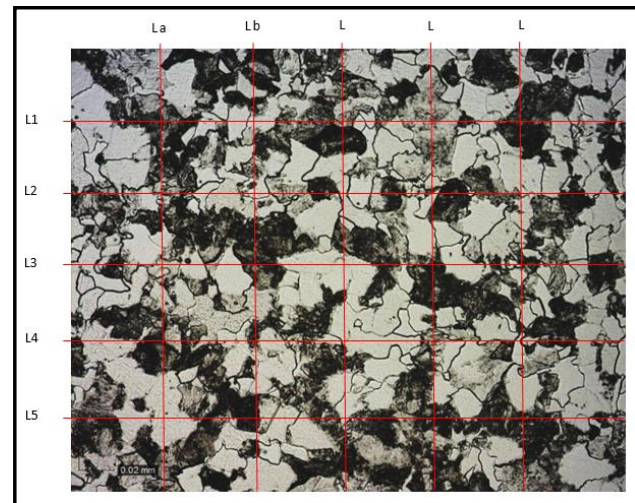

Gambar 19

Struktur mikro kondisi annealing, terlihat fasa ferrit (putih) + perlit (hitam)
Jadi, diperkirakan kandungan karbon yang terkandung pada bucket teeth adalah $0,42 \%$ C.

\subsection{Analisa Hasil Pemotretan Struktur Mikro}

\subsubsection{Kondisi as it is}

Pada pengamatan hasil pemotretan mikro struktur bucket teeth kondisi as it is bagian depan (Gbr 11 dan 12) terlihat fasa ferrit lebih banyak dibandingkan fasa martensit temper ini diakibatkan terjadi proses temper terusmenerus akibat gesekan dan benturan pada saat bucket teeth beroperasi sehingga menimbulkan panas yang menyebabkan harga kekerasan dibagian tepi berkurang.

Pada pengamatan hasil pemotretan mikro struktur bucket teeth kondisi as it is bagian tengah terlihat fasa martensit temper (Gbr 13, dan 14.) yang bentuknya runcing ini disebabkan oleh pendinginan yang sangat cepat dari temperatur austenit sehingga terbentuklah fasa martensit yang keras tapi getas. Kemudian dilakukan proses temper agar merubah sifat dari martensit tersebut, sehingga keuletan dan ketangguhan material meningkat.

Kemudian pada (Gbr 9) terlihat adanya porositas (ada pantulan cahaya dari dalam) akibat dari oksidasi sehingga udara terjebak pada saat proses pengecoran. 


\subsubsection{Kondisi annealing}

Pada pengamatan hasil pemotretan mikro struktur bucket teeth kondisi annealing (gbr 18 dan 19) terlihat struktur ferrit dan perlit dengan persentase ferrit $48,07 \%$ dan perlit $51,93 \%$. Diperkirakan kandungan karbon pada bucket teeth kurang dari 0,42\% berdasarkan metoda kuantitatif. Ini disebabkan oleh adanya pengaruh unsur paduan seperti $1,11 \% \mathrm{Si}$, $1,13 \% \mathrm{Cr}, 1,07 \%$ Mn dan $0.08 \%$ Mo apabila dipanaskan sampai temperatur austenit kemudian didinginkan dalam furnace maka akan menambah jumlah fasa ferrit dan perlit menjadi lebih banyak.

\subsubsection{Analisa Hasil Komposisi Kimia}

Berdasarkan hasil uji komposisi kimia, unsur paduan utama yang terdapat pada bucket teeth adalah sebagai berikut :

\section{Tabel 1}

Unsur paduan utama hasil uji komposisi kimia bucket

\begin{tabular}{|c|c|c|c|c|c|}
\hline & $\mathrm{C} \%$ & $\mathrm{Si} \%$ & $\mathrm{Mn} \%$ & $\mathrm{Cr} \%$ & $\mathrm{Mo} \%$ \\
\hline $\begin{array}{c}\text { Komposisi } \\
\text { kimia bucket } \\
\text { teeth }\end{array}$ & 0,26 & 1,11 & 1,07 & 1,13 & 0.08 \\
\hline & & & & & \\
DIN Grade & $0,22-$ & 0,4 & $0,6-$ & $0,9-$ & $0,15-$ \\
25 CrMo4 & 0,29 & $\max$ & 0,9 & 1,2 & 0,3 \\
\hline
\end{tabular}

Setelah dilakukan uji komposisi kimia, bucket teeth mempunyai kadar Karbon 0,26\% yang memiliki sifat meningkatkan kekuatan dan kekerasan, Silicon $1.11 \%$ yang membuat bucket teeth mempunyai sifat elastis/ keuletannya tinggi, silicon juga menambah kekerasan dan mampu cor pada baja lebih baik. Selain itu bucket teeth memiliki kadar Manganese sebesar $1,07 \%$ yang membuat bucket teeth, mempunyai sifat yang tahan terhadap gesekan dan tahan tekanan (impact load) serta meningkatkan kekuatan dan kekerasan, menurunkan laju pendinginan kritik sehingga mampu keras baja dapat ditingkatkan dan juga meningkatkan ketahanan terhadap abrasi. Kadar Chromium $1.13 \%$ yang terkandung dalam bucket teeth akan meningkatkan ketahanan korosi dan tahan terhadap gesekan yang dapat meyebabkan keausan. Kadar Molybdenum 0.08\% dapat meningkatkan ketahanan terhadap keausan, meningkatkan ketangguhan dan kekuatan pada temperatur tinggi dan jika berkombinasi dengan unsur paduan lainnya akan meningkatkan ketangguhan serta dapat meningkatkan ketahanan baja pada temperatur tinggi.

Berdasarkan hasil uji komposisi kimia, bucket teeth BWE mendekati spesifikasi standar DIN (Deutsche Industrie Norm) yang memiliki kode DIN Grade 25CrMo4 dan termasuk medium alloy steel karena elemen paduannya sebesar $3,39 \%$.

Dimana kandung yang dimiliki oleh bucket teeth BWE. Kandungan Mn sedikit melewati dari standar DIN Grade 25CrMo4 dan kandungan Si, Mo kurang sedikit dari standar 
DIN Grade 25CrMo4 ada kemungkinan material tersebut menggunakan acuan standar yang lain. Standar DIN Grade 25CrMo4 setara dengan standar AISI Grade SAE4130 dan JIS G 4051 Grade SCM420 penggunaan standar DIN Grade 25CrMo4 biasa di aplikasikan untuk pembuatan komponen struktur pasawat terbang, shaft roda mobil, bejana tekan dan lain-lain.

Dari dasil uji komposisi kimia kita dapat menghitung juga karbon ekivalen. Nilai karbon ekivalen menunjukkan hubungan antara kepekaan baja terhadap timbulnya retak dengan komposisi kimia baja. Jadi karbon ekivalen pada dasarnya mengindikasikan pengaruh unsur-unsur yang terkandung dalam material terhadap kemungkinan terjadinya retak. Dibawah ini adalah formula dan perhitungan nilai karbon ekivalen pada baja paduan [3].

$$
\begin{aligned}
& C E=C+\left(\frac{M n+S i}{6}\right)+\left(\frac{C r+M o+V}{5}\right)+\left(\frac{N i+C u}{15}\right) \\
& =0,26+\left(\frac{1,07+1,11}{6}\right)+\left(\frac{1,13+0,08+0,01}{5}\right)+\left(\frac{0,02+0,02}{15}\right) \\
& =0,26+0,36+0,24+0,002 \\
& =0,862 \%
\end{aligned}
$$

Maka semakin tinggi kosentrasi karbon dan elemen paduannya, maka semakin cenderung untuk meningkatkan kekerasan dan terjadinya retak apabila dilakukan proses pengelasan karena carbon equivalen maksimum adalah $0,5 \%$

\subsubsection{Pengujian Kekerasan dan Analisa}

Setelah diperkirakan bahwa proses pembuatan bucket teeth BWE dilakukan dengan proses cor dan tidak ada pengerasan, selanjutnya dipilih cara untuk uji keras yaitu dengan cara Brinell. Uji keras Brinell cocok untuk produk cor karena produk cor mempunyai struktur atau bentuk butir yang besar dan produk cor mempunyai porositas, untuk menjangkau bentuk butir yang besar dan adanya porositas maka digunakan uji keras Brinell yang mempunyai penampang indentor yang besar.

Spesimen yang digunakan untuk uji keras ini adalah kondisi as it is dan annealing arah pemotongan transversal dari bucket teeth. Indentor yang digunakan adalah bola baja berukuran $10 \mathrm{~mm}$ dengan beban uji $3000 \mathrm{kgf}$.

Tabel 2

Hasil Pengujian Kekerasan ( BHN )as it is

\begin{tabular}{|c|c|c|c|}
\hline No & $\begin{array}{c}\text { as it is } \\
\text { depan }\end{array}$ & $\begin{array}{c}\text { as it is } \\
\text { tengah }\end{array}$ & $\begin{array}{c}\text { as it is } \\
\text { belakang }\end{array}$ \\
\hline I & 464 & 477 & 471 \\
\hline II & 477 & 467 & 454 \\
\hline III & 464 & 474 & 467 \\
\hline Rata-rata & 468,3 & 472,6 & 464 \\
\hline
\end{tabular}

Catatan : harga kekerasan hasil annealing adalah 190 BHN

Dari hasil pengujian kekerasan kondisi as it is memiliki harga kekerasan rata-rata $468 \mathrm{BHN}$ dandianalisa tidak terdapat case hardening, 
karena harga kekerasan dibagian luar lebih rendah dibandingkan dibagian dalam. Ini disebabkan fasa ferrit lebih banyak dibagian luar dibandingkan dibagian dalam karena bucket teeth yang diuji adalah bucket teeth yang sudah beroperasi yang telah megalami gesekan dan benturan sehingga bucket teeth mengalami temper terus-menerus dan menyebabkan harga kekerasan dibagian luar lebih rendah dibandingkan dibagian dalam.

Sedangkan kondisi annealing memiliki harga kekerasan rata-rata 190 BHV. Setelah dianalisa jumlah fasa perlit dan ferrit menjadi banyak yang diakibatkan sampel dipanaskan sampai temperatur austenit kemudian unsur paduan $\mathrm{Si}, \mathrm{Cr}, \mathrm{Mn}$ dan Mo, ketika dipanaskan pada temperatur austenin bertransformasi menjadi fasa ferrit dan perlit sehingga jumlah fasa ferrit dan perlit menjadi lebih banyak.

Dari pegujian kekerasan brinell, kondisi as it is yang memiliki fasa martensit temper dan ferrit, memiliki harga kekerasan rata-rata 468,3 HBN dan diperkirakan temperatur penemperan sekitar $300^{\circ}-550^{\circ}$ yang membuat bucket teeth memiliki keuletan dan ketangguhan. Serta dipengaruhi unsur paduan $\mathrm{Si}, \mathrm{Mn}$, Mo dan $\mathrm{Cr}$ dimana unsur ini meningkatkan sifat kekerasan, akan tetapi unsur Si jika ditemper akan memiliki sifat kekuatan dan keuletan yang baik.
Sedangkan kondisi annealing yang memiliki fasa ferrit dan perlit memiliki harga kekerasan rata-rata $190 \mathrm{HBN}$, yang diakibatkan sampel dipanaskan sampai temperatur austenit kemudian unsur paduan $\mathrm{Si}, \mathrm{Cr}, \mathrm{Mn}$ dan $\mathrm{Mo}$, bertransformasi menjadi fasa ferrit dan perlit sehingga jumlah fasa perlit dan ferrit menjadi lebih banyak.

\section{KESIMPULAN}

Dari hasil penelitian yang telah dilakukan, maka diperoleh kesimpulan sebagai berikut :

1. Berdasarkan hasil uji komposisi kimia dapat diperkirakan material bucket teeth BWE mendekati spesifikasi standar DIN Grade 25CrMo4 yang mengandung kadar 0,26\% C, 1,11\% Si, 1,07\% Mn, 1,13\% Cr, dan $0,08 \%$ Mo.

2. Dilihat dari struktur mikro as it is meterial tersebut memiliki struktur martensit temper dan ferrit yang memiliki harga kekerasan bahan rata-rata 468,3 HBN.

3. Berdasarkan hasil annealing, struktur mikro material tersebut memiliki struktur ferit dan perlit dengan persentase ferit (48,07\%) dan perlit (51,93\%) dan memiliki harga kekerasan $190 \mathrm{HBN}$.

4. Berdasarkan pengamatan struktur makro diperkirakan bahwa bucket teeth diproduksi dengan proses cor menggunakan cetakan pasir kemudiandiikuti dengan heat treatment 
yang dapat dilihat dari struktur material tersebut.

\section{DAFTAR PUSTAKA}

[1] http://syafrilhernendi.com/bucket-wheelexcavator/, diakses tanggal 7/3/2013

[2] arsipteknikpertambangan.blogspot. com/, diakses tanggal 7/3/2013
[3] Smith. F.W, (1993), Structure and Properties of Engineering Alloy, $2^{\text {nd }}$ Edition, University of Central Florida.

[4] http://www.steelnumber.com/en/ steel_composition_eu.php?name_id=3 32/, diakses tanggal 15/1/2014.

[5] http://sekolah007.blogspot.com, diakses tanggal 15/1/2014 